\title{
Résumé of the Original Article in Japanese
}

Yoshitaka ImaI, Genetic Studies in Morning Glories

XIV. On the Factors rolling up the Leaves in Pharbitis Nil, with special reference to the Behavior of the "Punched" Leaves and their linked Characters

I. The factor or the factors, such as "Punched," "Sisi" and "Crapy" make the leaf-surface to roll up, and by the presence of one or more of these factors a varying series of "Roll-up" leaves results.

2. Two kinds of the "Punched" leaves were observed, each having an entirely different factor.

3. Both of the "Punched" factors behave as simple recessives to the normal. The factors interacten on each other, the results which being the appearance of the rolled leaves in the double of heterozygotic plants. Such a hybrid gives an $F_{2}$ composed of I I rolled and 5 normals in every I6 individuals.

4. One of the "Punched" factors, denoted by u", links to the variegated leaf factor $(v)$, and the other, named as $\mathrm{u}^{*}$, holds a similar relation to the "Sasa" leaf $\left(\mathrm{S}_{\mathrm{a}}\right)$.

5. The linkage value of $\mathrm{u}^{\mathrm{s}}$ and $\mathrm{s}_{\mathrm{i}}$ factors in about $5 \%$ (?) (=per cent. of cross-over).

6. The "Punched" combined with the "Crapy" produces the characteristic rolled up "Amaryō" leaves.

The Author

ERRATA in KOMURO'S paper of Vol. 38 : no. 445.

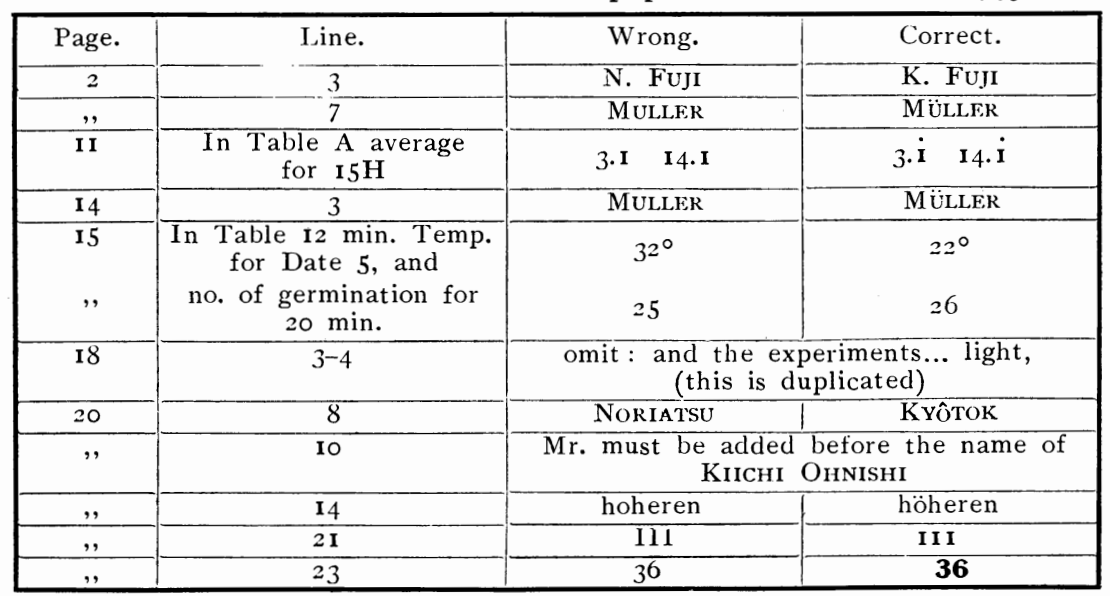

